\title{
Infecção experimental em suínos jovens com Leptospira interrogans sorovar wolffi: determinação de parâmetros bioquímicos
}

\author{
Experimental infection by Leptospira interrogans serovar wolffi in young pigs: Determination of \\ biochemical parameters
}

\author{
José Carlos Rende ${ }^{\mathrm{I}}$ Everlon Cid Rigobelo ${ }^{\mathrm{I}}$ José Moacir Marin' ${ }^{\mathrm{II}}$ Fernando Antonio de Ávila ${ }^{\mathrm{III}}$
}

\section{RESUMO}

Um estudo sobre infecção experimental foi realizado em oito suínos, com idade média de 90 dias, machos castrados, da raça Wessex, e distribuídos em dois grupos de quatro suínos cada. Durante 36 dias, foram analisadas as alterações bioquímicas nos soros dos suínos dos dois grupos. O Grupo I foi mantido como testemunho e recebeu 5,0mL de solução fisiológica estéril por via intravenosa (veia cava craniana) e, no Grupo II, os suínos foram inoculados pela mesma via com 5,0mL de cultura de Leptospira interrogans sorovar wolffi , amostra L-10 selvagem isolada de tatu (Dasypus novemcinctus), contendo $1,0 \times 10^{8}$ leptospiras $\mathrm{mL}^{-1}$. A partir do terceiro dia após a inoculação e em intervalos de 72 horas até o décimo oitavo dia, foram feitas coletas de sangue, sem anticoagulante, dos animais inoculados e testemunhas. Os parâmetros bioquímicos analisados foram: bilirrubina total, direta e indireta, ácidos graxos, glicose e proteínas plasmáticas. Foi detectado um aumento da bilirrubina direta no terceiro dia e um aumento no sexto dia da bilirrubina total e indireta após a inoculação. As dosagens de glicose, ácidos graxos e proteínas plasmáticas apresentaram uma diminuição a partir do terceiro dia da inoculação. Com os resultados obtidos, pode-se concluir que o aumento das taxas de bilirrubinas levam a uma definição de um diagnóstico de hemólise aguda, e que a hipoglicemia, a hipolipidemia e a hipoproteinemia podem estar relacionadas com lesões hepáticas e a uma septcemia.Todas as dosagens em todos os animais retornaram aos seus valores normais a partir do décimo quinto dia.

Palavras-chave: Leptospirose, suínos, infecção experimental, testes bioquímicos.

\section{ABSTRACT}

Eight, 90 days old pigs, of the Wessex lineage all castrated male were used in experiment, divided into two groups of four animals. Biochemical alterations in the serum of the

\begin{abstract}
animals were analyzed in both groups during 36 days. Control (Group I) received $5.0 \mathrm{~mL}$ of a $0.9 \%$ sterile sodium chloride solution by intracranial vein injection; Group II animals were inoculated by the same way with $5.0 \mathrm{~mL}$ of a cell culture containing $1.0 \times 10^{8} \mathrm{cells} \mathrm{mL}^{-1}$ of Leptospira interrogans sorovar wolffi, wild strain $L-10$, isolated from a wild especies of brazilian "armadillo" (Dasypus novemcinctus). Three days after inoculation, blood was collected without anticoagulant; the same process was repeated at 72 hours intervals during eighteen days in both, control and experimental groups. Quantitative biochemical parameters were direct, indirect and total bilirubin, fatty acids and serum proteins. The experimental animals showed an increase of direct bilirubin three days after inoculation. Increases in indirect and total bilirubin were, also, observed after six days. Glucose, fatty acids and serum proteins decreased after the third day of inoculation. In conclusion, the increase in bilirubin levels could be due to acute hemolysis; hypoglycemia, hypolipidemia and hypoproteinemia that could be related to hepatic lesions and septicemia. All parameters returned to normal levels after fifteen days, in all animals tested.
\end{abstract}

Key words: Leptospirosis, swine, experimental infection, biochemical tests.

\section{INTRODUÇÃO}

A leptospirose é uma doença zoonótica causada por bactéria da família Leptospiraceae, gênero Leptospira, que pode ser encontrada em várias partes do mundo. A infecção por leptospiras tem sido relatada em seres humanos, bovinos, suínos, eqüinos, caprinos cães, roedores e em diversas espécies de animais silvestres no Brasil e no mundo (SCHENCK, 1976; TRAGLIABUE \& FARINA, 1995).

'Programa de Pós-graduação em Microbiologia da Faculdade de Ciências Agrárias e Veterinária, Universidade Estadual de São Paulo (FCAV/UNESP), Campus Jaboticabal. Rodovia Paulo Donato Castellane Km 5, 14884-900, Jaboticabal, SP, Brasil. E-mail: favila@fcav.unesp.br ou everlonagro@yahoo.com.br. Autor para correspondência.

"Departamento de Morfologia, Estomatologia e Fisiologia da Faculdade de Odontologia, Universidade de São Paulo (USP), Ribeirão Preto, SP, Brasil. E-mail: jmmarin@forp.usp.br.

"I'Departamento de Patologia Veterinária, FCAV/UNESP, Campus de Jaboticabal, Jaboticabal, SP, Brasil. E-mail: favila@fcav.unesp.br. 
De acordo com OLIVEIRA (1988), a leptospirose é uma doença de manifestação aguda entre o terceiro e o décimo quarto dia após a infecção. Segundo RAMOS et al. (1981), essa doença pode-se tornar crônica após esse período e, nos últimos 30 anos, os suínos têm sido apontados como os mais importantes animais domésticos portadores de leptospira, sendo responsabilizados por ocorrências epidêmicas no homem e em outras espécies domésticas.

KiNGSCOTE (1986) relatou que Leptospira interrogans sorovar pomona poderia ser considerado o mais importante agente de problemas relacionados com falhas reprodutivas dos suínos; no entanto, POWER (1991), OLIVEIRA et al. (1994), GIRIO et al. (1998) e SCHÖNBERG et al. (2000) citam como causadores desses transtornos os sorovares bratislava e icterohaemorrhagiae. Vários estudos são encontrados na literatura sobre infecção experimental em suínos com diferentes sorovares leptospiras. BURNSTEIN \& BAKER (1954), WOODS et.al., (1962), STALHEIM (1973) induziram infecção com o sorovar pomona, HANSON et al. (1971) com o sorovar gripotyphosa, FARINA et al. (1977) com o sorovar bratislava e INZANA \& DAWE (1979) com o sorovar autumnalis.

Em suínos, dosagens bioquímicas no sangue envolvendo bilirrubinas, glicose, ácidos graxos e proteínas plasmáticas em resposta a infecções experimentais por leptospira são escassas na literatura. Segundo MORAIS et al. (2000), as dosagens bioquímicas no sangue podem auxiliar no diagnóstico, prognóstico e no tratamento de animais. De acordo com COLES (1984) e DOMAS \& WU (1991), a determinação das bilirrubinas representam um parametro para detectar hemólise aguda.

Considerando a alta incidência do sorovar wolffi relatada após um levantamento sorológico, em suínos com histórico de falhas reprodutivas, realizado em Minas Gerais por AVILA et al. (1977), o presente trabalho teve como objetivo relacionar os resultados bioquímicos com a infecção induzida por esse sorovar.

\section{MATERIAL E MÉTODOS}

Foram utilizados, no presente experimento, oito suínos da raça Wessex, machos castrados com aproximadamente 90 dias de idade, mantidos durante todo o experimento em baias cobertas e cimentadas. Os animais foram alimentados com ração $( \pm 0,8 \mathrm{~kg}$ suíno ${ }^{-1} \mathrm{dia}^{-1}$ ) e submetidos a idênticas condições usuais de manejo em suinocultura. Antes de se iniciar o experimento, todos os animais foram submetidos a exames clínicos e sorológicos (leptospirose, brucelose e toxoplasmose). Os animais foram distribuídos em dois grupos de quatro suínos cada: Grupo I - suínostestemunho e Grupo II - suínos-teste. O Grupo I foi mantido como testemunho e recebeu 5,0mL de solução fisiológica estéril por via intravenosa (veia cava craniana) e, no Grupo II, os suínos foram inoculados pela mesma via com 5,0mL de cultura de leptospira sorovar wolffi, amostra L-10 selvagem isolada de tatu (Dasypus novemcinctus), contendo 1,0 x10 $0^{8}$ leptospira $\mathrm{mL}^{-1}$.

Amostras de sangue $(5,0 \mathrm{~mL})$ dos suínos dos dois grupos foram obtidas por punção venosa da veia cava craniana, utilizando agulhas estéreis e tubos a vácuo estéreis sem anticoagulante, devidamente identificados, a partir do terceiro dia após a inoculação até o décimo oitavo dia, com intervalos de 72 horas entre cada coleta. Das amostras de sangue, foram obtidos soros e estes foram centrifugados sob refrigeração a 1.500r.p.m. durante 15 minutos. As amostras de soros foram colocadas em frascos de $5,0 \mathrm{~mL}$ estéreis e armazenados em congelador a $-20^{\circ} \mathrm{C}$ até $\mathrm{o}$ momento das análises.

As amostras de soros dos animais do Grupo II foram submetidas às seguintes dosagens: bilirrubina total e direta utilizando a técnica colorimétrica de SIMSHORN - Kit Labteste; ácidos graxos, segundo a técnica de DOLE \& MEINERTZ (1960); glicose, pelo método enzimático - glicose oxidase -Kit Labteste e proteínas plasmáticas determinadas pelo método do biureto KIT Labteste.As mesmas dosagens foram realizadas nos soros dos animais do Grupo I - testemunhos.

A analise de regressão linear $(\mathrm{P}<0,5)$ comparou os resultados dos testes bioquímicos entre os suínos do Grupo II inoculados com leptospira sorovar wolffi e os suínos do Grupo I inoculados com solução fisiológica estéril.

\section{RESULTADOS E DISCUSSÃO}

Na figura 1, são apresentados os resultados obtidos para a dosagem da bilirrubina total, direta e indireta, nos suínos do Grupo I, inoculados com solução fisiológica estéril e nos suínos do Grupo II inoculados com o sorovar wolffi. Pela análise dos dados, pode-se verificar um aumento significativo da bilirrubina total nos suínos do grupo inoculado comparado com os valores da bilirrubina total dos suínos do grupo testemunho. A partir do nono dia, não houve diferença significativa entre os testes de bilirrubina total dos dois grupos, cujos valores ficaram próximos dos níveis iniciais. O aumento da bilirrubina total, no sexto dia, nos animais infectados está de acordo com BACILA (2003) e BUSH (2004), que relataram uma hiperbilirrubenemia associada a uma hemólise aguda grave e hemopatias infecciosas. 


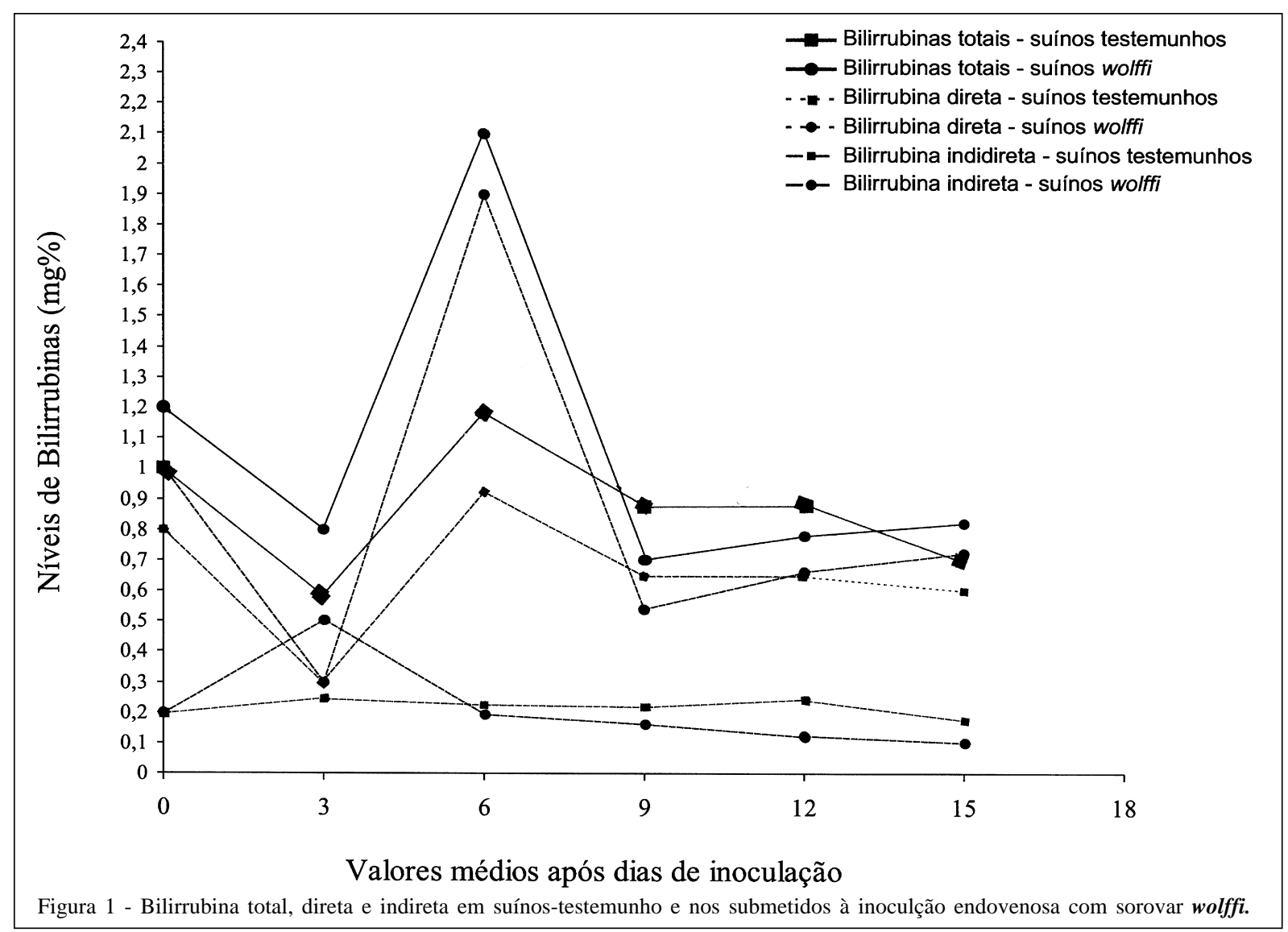

Na figura 1, também são apresentados os resultados obtidos para a dosagem de bilurrubina direta nos suínos dos Grupos I e II. Com relação ao Grupo II, observa-se um aumento nos níveis de bilirrubina direta no terceiro dia após inoculação, os quais voltaram aos valores iniciais a partir do sexto dia, não havendo mais alterações quando comparados com os valores dos suínos do Grupo I. Esse aumento de bilirubina direta no terceiro dia, observado nos suínos do Grupo II, pode ser devido a uma hemólise, o que indica que o fígado não apresenta nenhuma lesão e sugere uma eficiência na conjugação hepática da bilirrubina com o ácido glicurônico, o que está de acordo com MURRAY et al. (2000), que relataram que, quando há lesões hepáticas, essas provocam danos nas células hepáticas parenquimatosas, dificultando a conjugação.

Quanto aos valores de bilirrubinas indiretas, pode-se observar que, entre o início do experimento e o terceiro dia, houve uma diminuição seguida de um aumento dos níveis no sexto dia, nos animais inoculados com o sorovar wolffi e que, a partir do nono dia, foi verificado uma queda nos valores, que se mantiveram estáveis até o décimo quinto dia. Um comportamento semelhante foi observado nos suínos testemunho, entretanto esse aumento da bilirubina indireta, nesse grupo, foi discreto quando comparado aos animais inoculados. Essa diminuição do nível de bilirrubina indireta no terceiro dia após a inoculação com soro sorovar wolffi está de acordo com BUSH (2004), que relatou que, após uma hemólise, a bilirrubinemia indireta não é aparente nas primeiras horas. O aumento acentuado da bilirrubina indireta no sexto dia parece indicar uma hemólise excessiva, o que está em acordo com BRETCHER \& BESSIS (1972) e BESSIS (1973). Esses autores relataram que algumas toxinas bacterianas provocam alteração no metabolismo dos carboidratos das hemácias com uma conseqüente diminuição de ATP. Essa seria uma possível explicação para a perda da motilidade do sistema contrátil da membrana das hemácias. Também, segundo THOMPSON \& MANKTELOW (1986), essa perda de motilidade provoca uma alteração na morfologia do eritrócito, passando de disco bicôncavo para uma forma esférica (esferocitose). Essa anormalidade resultaria na detecção e remoção das células esferocíticas, pelo sistema retículo-macrófago (baço, fígado, medula óssea), onde seriam destruídas com liberação de hemoglobina, que seria transformada em bilirrubina.

Na figura 2 estão os resultados das dosagens de ácidos graxos nos suínos dos dois 


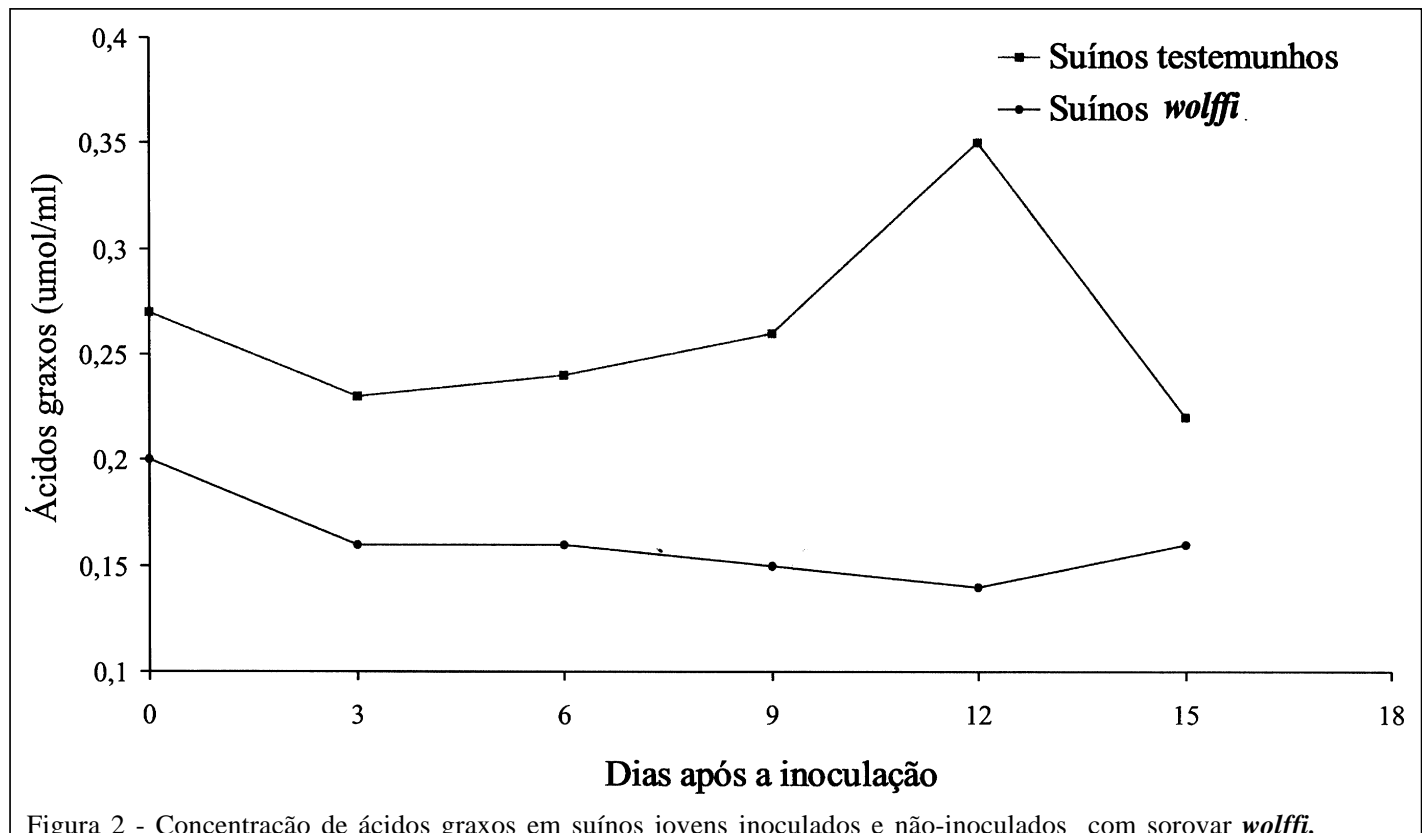

grupos. Observa-se uma queda dos níveis de ácidos graxos nos suínos inoculados, enquanto nos suínos do grupo testemunho há uma queda e logo em seguida uma elevação, sendo o maior valor detectado no décimo segundo dia. A diminuição dos ácidos graxos nos suínos inoculados com o sorovar wolffi está de acordo com MURRAY et al. (2000), que relataram que uma hipolipidemia é secundária a uma hipoglicemia.

$\mathrm{Na}$ figura 3, verifica-se que os níveis de glicose apresentam uma diminuição até o terceiro dia após a inoculação, seguida de aumento constante até ultrapassar, no décimo quinto dia, os valores iniciais. No grupo testemunho, também verificou-se uma queda das taxas de glicose, seguida de aumento a partir do terceiro dia, atingindo o valor máximo no nono dia e diminuindo a valores menores do que os iniciais entre o décimo segundo e o décimo quinto dia. A hipoglicemia observada está de acordo com LATIMER et al. (2003), que relataram a ocorrência de um aumento do consumo de glicose pelos tecidos, em caso de septicemia.

As dosagens de proteínas plasmáticas estão mostradas na figura 4 . Não foram verificadas alterações

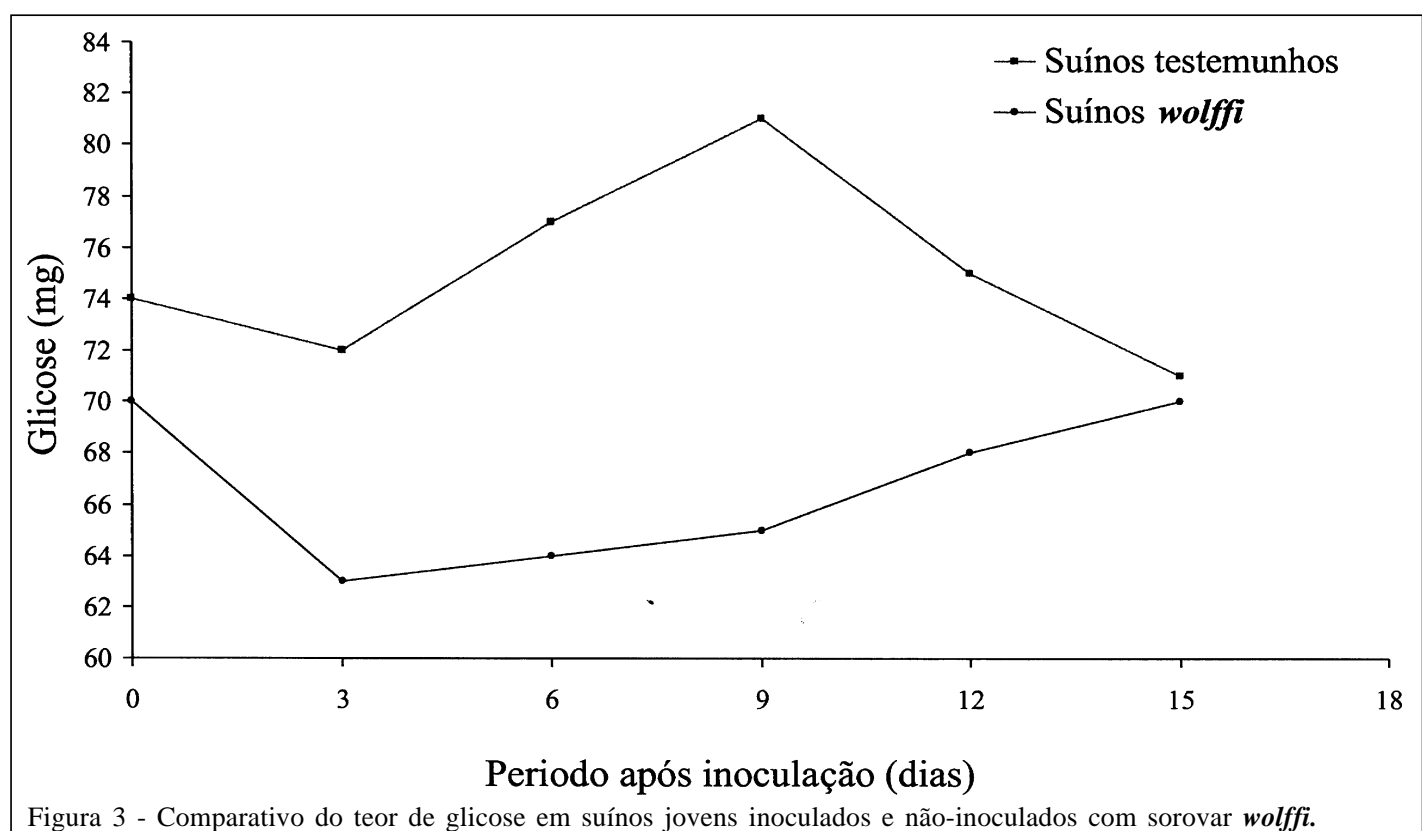

Ciência Rural, v.37, n.2, mar-abr, 2007. 


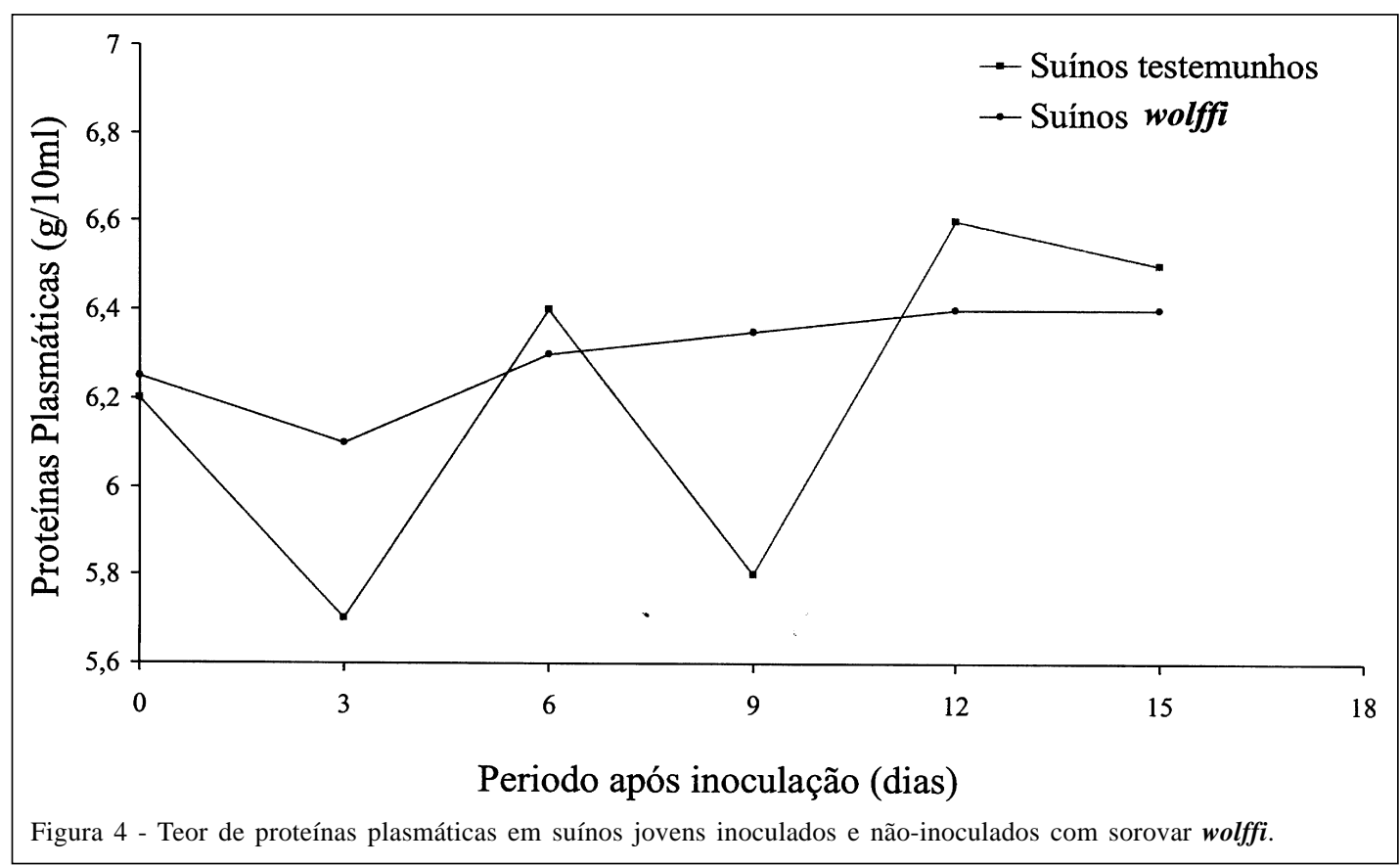

significativas nos níveis de proteínas plasmáticas, apesar de haver uma diminuição no terceiro dia, nos suínos do Grupo II, após a inoculação com sorovar wolffi. Essa hipoproteinemia nos animais inoculados, poderia estar relacionada com uma discreta lesão hepática, que pode ter sido provocada pela infecção leptospírica (BURTIS \& ASHWOOD, 1998). BUSH (2004) relata que, em casos de septicemia e bacteremia, pode haver um aumento da permeabilidade capilar que permite o extravasamento de albumina para compartimentos extravasculares, o que possivelmente poderia comprovar a septicemia ter começado no terceiro dia neste experimento.

\section{CONCLUSÕES}

Pode-se concluir que o modelo de indução de leptospirose mediante a inoculação intravenosa do sorovar wolffi mostrou-se efetivo. As variações bioquímicas no sangue dos suínos inoculados com sorovar wolfii foram: hipolipidemia, hipoglicemia e hipoproteinemia, sugerindo uma lesão hepática e septicemia bacteriana. A hiperbilirrubinemia pode indicar que a principal causa da toxidade do sorovar wolffi, neste trabalho, é uma anemia hemolítica grave.

\section{REFERÊNCIAS}

ÁVILA, F.A. et al. Freqüência de aglutininas anti-leptospiras em soros de suínos de Minas Gerais. Arquivo da Escola de Veterinária da UFMG, Belo Horizonte, v.29, n.3, p.263268, 1977.
BACILA, M. Bioquímica veterinária. 2.ed. São Paulo: Robe Editorial, 2003. 583p.

BESSIS, M. Living blood cells and their ultrastructure. New York: Springer Verlag, 1973. 717p.

BRETCHER, G.; BESSIS, M. Present status of spiculed red cell, and their relationship to the discotype-echionocyte transformation: a critical review. Blood, v.40, p.333-344, 1972.

BURNSTEIN, T.; BAKER, J. Lepstospirosis in swine caused by Leptospira Pomona. Journal of Infectious Diseases, New York, n.94, p.52-64, 1954.

BURTIS, C.A.; ASHWOOD, E.R. Fundamentos de química clínica. 4.ed. Rio de Janeiro: Guanabara Koogan, 1998. 842p.

BUSH, B.M. Interpretação de resultados laboratoriais para clínicos de pequenos animais. São Paulo: Roca, 2004. $276 \mathrm{p}$.

COLES, E.H. Função hepática. In: COLES, E.H. Patologia clínica veterinária. 3.ed. São Paulo: Manole, 1984. p.185219.

DOLE, V.F.; MEINERTZ, H. Microdetermination of long chain fatty acids in plasma and tissues. Journal of Biology and Chemistry, v.235, p.25-95, 1960.

DOMAS, B.T.; WU, T.Y. The measurement of bilirubin fraction in serum. Critical Reviews in Clinical Laboratory Science, v.28, p.415-445, 1991.

FARINA, R. et al. Leptospirosis in swine: experimental infection with serotype bratislava. International Journal of Zoonosis v.4, p.38-44, 1977.

GIRIO, R.J.S. et al. Alterações reprodutivas e anatomopatológicas em fêmeas suínas com títulos de anticorpos contra Leptospira 
interrogans sorotipo icterohaemorrhagiae. Revista Brasileira de Ciência Veterinária, v.5, n.3, p.99-103, 1998.

HANSON, L.E. et al. Leptospirosis in swine caused by serotype grippotyphosa. American Journal of Veterinary Research, v.32, n.6, p.855-860, 1971.

INZANA, T.J.; DAWE, D.L. Experimentally induced Leptospira interrogans serovar autumnalis infections in young swine. American Journal of Veterinary Research, v.40, n.10, p.1355-1358, 1979.

KINGSCOTE, B.F. Leptospirosis outbreak in Piggery in Southern Alberta. Canadian Veterinary Journal, n.27, p.188-190, 1986.

LATIMER, K.S. Veterinary laboratory medicine: clinical pathology. 4.ed. Iowa: A Blackwell, 2003. 450p.

MORAIS, M.G. et al. Variação sazonal de bioquímica clínica de vacas aneloradas sob pastejo contínuo de Brachiara decumbens. Arquivo de Medicina Veterinária e Zootécnica v.52, n.9, p.98-104, 2000.

MURRAY, R.K. et al. Harper's biochemistry. 25.ed. Connecticut: Appleton \& Lauge, 2000. 927p.

OLIVEIRA, S.J. Leptospirose em Suínos. A Hora Veterinária, ano.7, n.41, p.5-8, 1988

OLIVEIRA, S.J. et al. Evidências de infecção por Leptospira bratislava em transtornos reprodutivos em suínos. Ciência Rural, v.24, n.2, p.345-348, 1994.
POWER, S.B. Diagnosing Leptospira in pigs. Veterinary Record, v.128, p.43, 1991 .

RAMOS, A. et al. Inquérito sociológico de leptospirose em suínos no Estado do Rio de Janeiro e região limítrofe. Pesquisa Veterinária Brasileira, v.1, n.3, p.81-83, 1981.

SCHENCK, J.A.P. Isolamento de leptospira do sorogrupo hebdomadis de tatus (Dasypus novemcintus) capturados no Estado de Minas Gerais. 1976. 75f. Dissertação (Mestrado em Medicina Veterinária Preventiva) - Curso de Pós-graduação em Medicina Veterinária, Universidade Federal de Minas Gerais.

SCHÖNBERG, A. et al. Leptospira interrogans serovar bratislava in pig breeding herds. In: GERMANY INTERNATIONAL LEPTOSPIROSIS SOCIETY, 3., 2002, Bridgetown, Barbados. Proceedings... Bridgetown, Barbado: Internacioanl Leptospiros Society, 2002. 276p. p.49.

STALHEIM, O.H.V. Urinary precipitate in porcine leptospirosis. Cornell Veterinary, v.64, p.20-24, 1973

TAGLIABUE, S.; FARINA, R. Inchesta sieroepidemiologica sulla diffusione delle leptospirosi tragli animali domestici ed alcune specie selvatiche. Selezione Veterinária, v.36, n.1112, p.941-953, 1995

THOMPSON, J.C.; MANKTELOW, B.W. Pathogenesis and red blood cell destruction in haemoglobinaemic leptospirosis. Journal of Comparative Pathology, v.96, p.529-538, 1986.

WOODS, G.T. et al. Experimental infection of swine with Leptospira ballum. Zoonoses Research, New York, v.1, n.10, p.165-184, 1962. 